\title{
Compreendendo a trajetória de mulheres em busca do diagnóstico e tratamento do câncer de mama: uma perspectiva sócio - antropológica
}

Comprehending the trajectory of women in search for diagnosis and treatment for breast cancer: a socio-anthropologic perspective

\author{
Autora: Márcia Marília Vargas Fróes Skaba
}

Orientador: Prof. ${ }^{\circ}$ Dr. ${ }^{0}$ Romeu Gomes

\section{Resumo}

A presente investigação tem como objeto de estudo o itinerário que mulheres portadoras de câncer de mama matriculadas em hospital especializado do Instituto Nacional de Câncer percorrem em busca do diagnóstico e início do tratamento. O objetivo do trabalho é analisar o significado do adoecimento por câncer de mama para as mulheres estudadas, estabelecendo relações entre as representações atribuídas a essa doença e a construção de determinado itinerário em busca do diagnóstico e tratamento. O estudo tem como bases teórico-metodológicas as representações sociais do câncer e o itinerário terapêutico. Acreditamos que, ancoradas numa reflexão teórica realizada nos campos da sociologia e da antropologia, essas categorias dão maior visibilidade ao nosso objeto de estudo. Sublinhamos que a investigação é de natureza qualitativa, embora análises quantitativas tenham servido de cenário para as construçôes sociológicas e antropológicas desenvolvidas. Realizamos 25 entrevistas semi-estruturadas, buscando compreender as experiências das pacientes no desenvolvimento de um itinerário terapêutico e suas representações sociais sobre o Câncer de Mama, com vistas à comparação desses aspectos ao favorecimento - ou não - na obtenção do diagnóstico desta patologia. Nas considerações finais, dentre outras recomendaçôes, ressaltase a urgente necessidade da abordagem do câncer em uma perspectiva interdisciplinar, superando a visão biomédica, hegemônica nas formulações de políticas de prevenção e tratamento.

Tese apresentada ao Programa de Pós-Graduação do Instituto Fernandes Figueira da Fundação Oswaldo Cruz, para obtenção do título de doutor em ciências. Rio de Janeiro, 2003. 